\title{
Modelo assistencial e estratégia saúde da família no nível local: análise de uma experiência
}

\author{
Health care model and the family health strategy \\ in the local level: analysis of an experience
}

Mônica de Castro Maia Senna 1

Mirian Miranda Cohen 2

\footnotetext{
1 Universidade Federal Fluminense. Travessa Washington Luiz, 317. Porto da Madama 24431-130 São Gonçalo RJ. marcossenna@uol.com.br

2 Fundação Municipal de Saúde de Niterói.
}

\begin{abstract}
This paper examines the impact produced by the implementation of the family's health strategy in the organization of the local services. It takes as reference the experience of the Family Doctor Program (PMF) in Niterói/ $R J$. According to the study, the adoption of PMF was stimulated by the progress of health decentralization in course in the country. It discusses the perspective of inauguration of a new health care model in basis of three central subjects: a) the relationship with the local health system; $b$ ) the social control and c) the administration of human resources in health. The author conclude that the health care model is not given a priori, but it is built in the day by day of the political relationships among social actors with differentiated degrees of incorporation of its demands for the government. In consequence, various retranslations of the model originally proposed arise.
\end{abstract}

Key words Decentralization, Municipalization, Health care model, Family health strategy
Resumo Este artigo examina o impacto produzido pela implantação da estratégia saúde da família na organização dos serviços locais, tomando como referência a experiência do Programa Médico de Família (PMF) em Niteróil RJ. Parte-se do entendimento de que a adoção do PMF foi impulsionada pelo avanço do processo de descentralização setorial em curso no país. Discute-se a perspectiva de inauguração de um novo modelo assistencial com base em três temas centrais: a) a relação com o sistema local de saúde; b) a questão do controle social; e c) a gestão de recursos humanos em saúde. Entende-se que o modelo assistencial não é dado a priori, mas construído no cotidiano das relações políticas entre atores sociais com graus diferenciados de incorporação de suas demandas pelo poder público, o que dá lugar a retraduções diversas do modelo proposto por esta política.

Palavras-chave Descentralização, Municipalização, Modelo assistencial em saúde, Saúde da família 


\section{Introdução}

A descentralização municipal da saúde, uma das diretrizes básicas para a implantação do Sistema Único de Saúde (SUS) no país, tem se constituído em estratégia definidora de uma nova agenda para o setor. Ao longo dos anos 90, este processo consolidou a reestruturação da arena decisória em torno da saúde, com transferência de responsabilidades e recursos financeiros aos municípios.

Se por um lado tal processo é ainda hoje marcado por incertezas quanto a seu alcance e implicações, por outro, ele tem revelado um campo fértil de experiências municipais inovadoras, seja quanto ao incremento da oferta de serviços, seja em relação à reorganização do modelo assistencial, ou ainda à revisão das formas de relação público/privado, entre outros aspectos.

De fato, na última década, o nível local tem se configurado como campo essencial para a análise de como a descentralização tem se refletido na conformação do modelo assistencial, tendo em vista as relações estabelecidas entre os diversos atores sociais privilegiados no processo de reforma setorial vis-à-vis à influência da macroconjuntura.

Este artigo toma como objeto de análise o Programa Médico de Família (PMF) no município de Niterói, região metropolitana do Rio de Janeiro, como uma experiência inovadora nos marcos do processo de municipalização da saúde. O desafio aqui proposto consiste em conhecer o impacto deste programa no padrão da oferta dos serviços de saúde no município, a partir da diversidade de concepções e interesses dos vários atores sociais, bem como o grau de inclusão/exclusão dos mesmos na agenda setorial.

Podemos tomar setembro de 1992, data de inauguração oficial do primeiro módulo do PMF, como a pedra fundamental do processo de implementação do programa em Niterói. Se esta inauguração formaliza o programa, nosso interesse maior reside, contudo, na possibilidade de acompanhar sua trajetória em diversos momentos, quando atores diferenciados adquirem maior ou menor visibilidade e quando as tensões entre a tradicional forma de intermediação de interesses e as perspectivas de imprimir às ações de saúde padrões de eqüidade social ganham relevância.

Nesta direção, a idéia básica deste trabalho é analisar as mudanças produzidas pelo PMF no modelo assistencial, considerando o desloca- mento do processo decisório para o nível local. Destacamos três aspectos essenciais dentro dos quais o programa apresentaria potencial para produzir inovações no modelo de atenção à saúde no município: a) a relação com o sistema local de saúde; b) a questão do controle social; e c) os recursos humanos em saúde.

A perspectiva de inauguração de um novo modelo assistencial que o PMF encerra é discutida a partir da concepção de que o perfil da oferta dos serviços de saúde expressa arranjos construídos nas relações entre Estado e atores sociais com graus diferenciados de incorporação de suas demandas (Senna, 1995). Assim, ao contrário das abordagens técnico-normativas, aponta-se que o modelo assistencial não é dado a priori, mas constrói-se no cotidiano das relações políticas entre os diversos atores sociais. Desse modo, é a arena de interesses em torno do PMF quem redefine o desenho técnico-institucional desta política, dando lugar a retraduções diversas do modelo traçado pelo poder público, com impacto direto no perfil da oferta dos serviços de saúde do município.

\section{Descentralização municipal e gestão local da saúde}

Os anos 90 são marcados pelo aprofundamento do processo de descentralização da saúde em direção aos municípios como uma das diretrizes básicas da reforma setorial. A implantação do SUS, a partir do início da década, tem redesenhado os contornos da atenção à saúde no país, redefinindo as responsabilidades e competências de cada nível de governo e atribuindo aos municípios papel central na gestão do sistema local de saúde.

O conjunto de alterações que vem ocorrendo no âmbito da política de saúde se circunscreve no processo recente de revisão das relações Estado/sociedade, onde novas requisições quanto ao papel do Estado se colocam na ordem do dia. Com efeito, a discussão contemporânea em torno da descentralização do Estado e do fortalecimento dos governos locais tem início na Europa, a partir de meados da década de 1970, com o desenvolvimento de profundas reformas institucionais direcionadas à descentralização do Welfare State e à organização da gestão territorial dos processos econômicos, sociopolíticos e administrativos. O debate em torno da descentralização situa-se, assim, no contexto de uma aguda crise capitalista dos países desenvolvidos, 
muito embora não possa ser reduzido a uma mera resposta a estes condicionantes mais amplos. Vários países atravessaram uma onda de reformas dos seus sistemas de serviços de saúde ao longo dos anos 80 e 90 tendo a descentralização desempenhado importante papel nos processos de reforma setorial. Esta onda, no entanto, teve cursos e impactos distintos em cada país, onde o significado e o alcance deste processo variaram em cada contexto histórico nacional (Almeida, 1999).

Na América Latina, a maioria dos países vem tentando adaptar-se às novas condições da economia mundial e às restrições fiscais, através da adoção de uma série de medidas de ajuste tais como eliminação de funções governamentais, cortes nos gastos públicos, redução da folha de pessoal, privatização, desregulamentação e descentralização. Implicam, assim, a tentativa de revisão do papel desempenhado pelo Estado de principal indutor do crescimento econômico e prestador de serviços sociais (Souza \& Carvalho, 1999).

No caso brasileiro, para além deste contexto mais amplo, a descentralização vem ocorrendo em meio a alterações significativas na natureza das relações intergovernamentais $v i s-\grave{a}$-vis ao resgate das bases federativas do Estado, já a partir de meados dos anos 80 . Nesta direção, as políticas sociais constituem eixo central na análise do processo de redefinição do pacto federativo e da descentralização em curso no país, pari passu ao esgotamento do padrão de desenvolvimento e ao desgaste do modelo político autoritário (Almeida, 1996).

É preciso considerar ainda, para além destas questões, as especificidades do processo de descentralização da política de saúde no Brasil, decorrentes da dinâmica própria do setor e da implementação do SUS. Pode-se dizer que, ao final dos anos 90, a engenharia institucional do setor saúde no país foi reformatada, com a transferência de atribuições de gestão aos níveis subnacionais, especialmente os municípios. A implementação do SUS trouxe o município como espaço privilegiado na gestão dos serviços de saúde, acarretando a necessidade de recuperação dos atores políticos e das instituiçõos que definem o sistema local. Neste sentido, é fundamental perceber que a descentralização é um processo que envolve a definição de novos atores sociais e novas formas de relação público/ privado que esbarram com freqüência em mecanismos e atores políticos tradicionais (Bodstein, 1996).
Ao mesmo tempo, não se pode esquecer as profundas desigualdades existentes no Brasil, as quais se refletem em fortes diferenças nas condições financeiras, políticas e administrativas dos municípios, o que interfere na sua capacidade de respostas às necessidades e demandas da população (Souza \& Carvalho, 1999).

O deslocamento do processo decisório para os municípios introduz, portanto, um conjunto de incertezas e acarreta impactos os mais diversos na organização dos serviços. Verificam-se tanto experiências exitosas no tocante à ampliação do acesso aos serviços e redefinição do modelo assistencial quanto outras em que o padrão anterior de organização da atenção à saúde não foi em nada alterado. De qualquer forma, a crescente autonomia municipal tem aberto a possibilidade de ricas experiências locais com potencial para produzir inovações as mais variadas no padrão de atenção à saúde sob gestão local.

É nesta perspectiva que analisamos o processo de formulação e implementação do Programa Médico de Família em Niterói. Certamente a transferência da gestão da saúde para o município em muito contribuiu para que um programa do porte do PMF pudesse ser formulado, encerrando a perspectiva de inauguração de um novo modelo assistencial no nível local. Ao mesmo tempo, os contornos assumidos pela descentralização da gestão têm interferido no processo de implementação do Programa, tanto quanto a arena decisória local influencia o alcance da descentralização na reorganização da atenção à saúde.

\section{Algumas características do município de Niterói}

Niterói é um município da Região Metropolitana do Rio de Janeiro, com uma área territorial de $132 \mathrm{~km}^{2}$ e uma população de 458.465 habitantes, segundo o Censo/IBGE 2000. Trata-se de um município de médio porte, com densidade demográfica de $3.487 \mathrm{hab} / \mathrm{km}^{2}$, sendo o quinto município mais populoso do estado.

Em termos de infra-estrutura urbana, o município possui 76,56\% dos domicílios com água encanada, $65,74 \%$ com rede de esgoto sanitário e 86,02\% com recolhimento regular de lixo (PMN/Secitec, 1999). É considerada a quarta cidade em qualidade de vida do país e a primeira do estado do Rio de Janeiro, de acordo com o Índice de Qualidade de Vida (IQV-UFF), 
elaborado pela Universidade Federal Fluminense (PMN/Secitec, 1999), possuindo, ainda, um dos IDH-M mais altos do Brasil - 0, 821, ocupando a primeira posição no estado e a décimaquinta no país.

Apesar de registrar bom nível de instrução de sua população, uma taxa de urbanização de $100 \%$ e uma renda média e potencial de consumo elevado, o município apresenta grandes desigualdades sociais, coexistindo, em alguns espaços, condomínios de alto luxo e áreas favelizadas, características do fenômeno de metropolização da pobreza.

De forma geral, os moradores de Niterói usufruem uma extensa rede de equipamentos de uso coletivo e de serviços, incluindo-se aí a rede de saúde, o que se deve, em parte, à herança da condição de capital do antigo estado do Rio de Janeiro. Em relação à oferta de serviços de saúde, pode-se afirmar que o município possui um setor público com capacidade instalada acima da média nacional, sendo o segundo do estado do Rio de Janeiro. A extensa rede de serviços no município ocasiona uma grande procura por parte da população residente em outros municípios, o que certamente interfere na organização e gestão do sistema local de saúde.

O Município de Niterói pode ser reconhecido como um dos pioneiros na adoção de estratégias de organização do sistema local de saúde, baseadas nas diretrizes de integração interinstitucional, hierarquização e integralidade das ações sanitárias e participação popular. Estas diretrizes norteavam, já no início dos anos 80 , as AIS (Ações Integradas de Saúde) e, posteriormente, o SUDS (Sistema Unificado de Saúde), precursores do SUS. O Projeto Niterói (19821988) foi, neste sentido, uma das experiências pioneiras e exitosas de ações integradas de saúde no país e teve sua dinâmica particularmente afetada pelos embates de interesses no nível local (Silva Jr. \& Oliveira, 1993).

Em 1989, Niterói assumiu uma nova configuração política, quando uma coalizão de orientação progressista elegeu o novo prefeito, o qual acolheu a indicação proveniente do movimento sanitário local do então secretário executivo do Projeto Niterói para o cargo de secretário municipal de saúde. Na verdade, o Projeto Niterói forneceu vários profissionais à Secretaria $\mathrm{Mu}$ nicipal de Saúde, o que contribuiu no processo de municipalização da saúde e na recomposição do sistema local.

Os anos 90 iniciaram-se com uma grande efervescência política em torno da municipali- zação da saúde. O governo municipal de Niterói, recém-empossado, deu início à implantação efetiva do SUS, direcionada para os princípios básicos de universalidade, acesso, integralidade e eqüidade. Dessa forma, a partir de 1989, concretizaram-se a regionalização e a descentralização das ações de saúde através da implantação dos Distritos Sanitários, buscando-se viabilizar a proposta de adscrição de clientela. Foi neste momento também que se iniciou o processo de transferência para o município das unidades federais e estaduais, além dos serviços de vigilância sanitária e epidemiológica.

Pode-se afirmar que o processo de municipalização em Niterói se efetivou em curto espaço de tempo, tendo se concretizado no período de 1989 a 1992. Houve uma rápida expansão da rede de assistência à saúde sob gestão municipal, o que levou a modificações estruturais no desenho institucional do SUS - Niterói. Se em 1989 a Secretaria Municipal de Saúde tinha sob sua gestão 13 postos de saúde e dois serviços de pronto atendimento (SPA), em 1993 passou a gerir uma rede complexa composta por três módulos do PMF, 14 Unidades Básicas de Saúde, seis PAMs/Centro de Saúde, três SPAs, quatro postos de saúde, três hospitais, três laboratórios, um Centro de Controle de Zoonoses e um Centro de Tecnologia de Alimentos. Tais alterações expressam, em grande medida, um extenso processo de pactuação em torno dos grupos de interesses no nível local.

A Secretaria Municipal de Saúde incorporou à sua estrutura a Fundação Municipal de Saúde (FMS) - entidade pública que tem como presidente o próprio secretário de Saúde - e várias outras instâncias de gestão, a fim de viabilizar o gerenciamento de uma gama de unidades e serviços incorporados ao SUS. Ao ser criada em fins de 1990, a FMS nasceu com total autonomia em relação à Prefeitura, sendo responsável pela gestão do Fundo Municipal de Saúde.

Em 1991, foi realizada a 1ạ Conferência Municipal de Saúde, que elegeu o Conselho Municipal de Saúde, formado por usuários, profissionais de saúde e membros do poder público. $\mathrm{O}$ conselho tem caráter deliberativo e constitui-se, ao menos em tese, na instância decisória da política de saúde no nível local. À época, havia ainda um Conselho Diretor da Fundação, composto pelo secretário de Saúde, gestores, profissionais e usuários, que possuía um caráter executivo.

O desenho do setor saúde sob gestão do município sofreu, assim, enormes mudanças e assumiu a configuração de uma rede hierarquiza- 
da e integrada, como fruto de um acelerado processo de descentralização. Para Cohen (2001), este fato provocou dificuldades na organização do sistema local, até mesmo na própria estruturação da máquina burocrática. $\mathrm{O}$ quadro técnico foi constituído à medida que a incorporação de novas estruturas gerava a necessidade de agregar novos atores para a execução e a gerência das ações de saúde, agora sob a responsabilidade da gestão municipal.

O processo de municipalização, com a incorporação de novas unidades, introduziu a necessidade de revisão das bases do modelo assistencial local. Esta perspectiva foi reforçada quando, nos anos 89 e 90, o município vivenciou uma epidemia de dengue hemorrágica (8990) e uma incidência elevada de casos de meningite meningocócica (90). Neste contexto, houve uma forte aproximação com Cuba, devido à alta tecnologia desenvolvida por esse país no campo das imunizações, sobretudo para meningite, favorecendo um intercâmbio que mais tarde redundaria na aplicação do modelo de medicina familiar cubano adequado à realidade local.

Vale ressaltar que várias alternativas foram formuladas no município, na perspectiva de consolidação de um modelo assistencial capaz de responder às necessidades da população, expressando alguns dos conflitos entre distintos atores no nível local e a necessidade de pactuações. O fato é que as dificuldades oriundas do processo de municipalização da saúde no contexto nacional e local, com as descontinuidades de repasse de verba e a falta de respostas mais concretas aos problemas de saúde da população, contribuíram para que se buscasse no Programa Médico de Família a possibilidade de reorientação do modelo.

\section{A configuração do Programa Médico de Família em Niterói}

A idéia de construção de um modelo assistencial baseado nos princípios de hierarquização, regionalização, integralidade e adscrição de clientela já constituía parte da agenda do setor saúde em Niterói desde a década de 1980, nos marcos das AIS e do Projeto Niterói. No entanto, foi com o avanço do processo de municipalização da saúde que se criaram as condições favoráveis para a formulação de um programa com as características do PMF.

Em 1991, com a visita do então prefeito de Niterói e do secretário municipal de saúde a
Cuba, fruto do intercâmbio firmado para enfrentar as epidemias de dengue e de meningite no município, concretizou-se um conjunto de decisões políticas para adaptar a experiência cubana de medicina familiar à realidade local. No mesmo ano foram realizados estudos preliminares no sentido de formular um projeto piloto, com a colaboração e assessoria técnica do Ministério de Saúde Pública cubano, através da figura do diretor do policlínico docente de Lawton/Havana, pioneiro no desenvolvimento do modelo daquele país. Esse profissional continua, ainda hoje, a ter forte ligação com o Programa Médico de Família em Niterói.

Em sua formulação, o PMF foi estruturado através de uma equipe coordenadora municipal, a cargo da então Superintendência de Ações Integradas de Saúde da Fundação Municipal de Saúde (atual Vice-presidência de Atenção Coletiva, Ambulatorial e da Família). A equipe coordenadora era composta ainda pelo secretário de Saúde e pela assessoria cubana, sendo diretamente ligada ao gabinete do secretário de Saúde. Uma das atribuiçõoes desta equipe era discutir a aplicabilidade do modelo cubano às características sociais, políticas e culturais do sistema local de saúde, levando em conta os princípios e diretrizes do SUS.

A proposta de reorganização do sistema local a partir do PMF teve sua primeira experiência concreta em setembro de 1992, com a implantação do primeiro módulo do programa na comunidade do Preventório. No mesmo ano, foram inaugurados outros dois módulos: o do morro do Viradouro, em outubro, e o do morro do Cavalão, em novembro.

Atualmente, o PMF conta com 64 equipes básicas distribuídas em 18 módulos, atingindo pouco mais de $14 \%$ da população do município.

A perspectiva dos gestores municipais é a de que o PMF configuraria a implantação de um novo padrão de assistência à saúde no município. A novidade residiria no estabelecimento de uma nova relação médico-paciente, na revisão da prática médica, na forma de contratação, capacitação, supervisão e avaliação dos profissionais e na parceria entre governo municipal e associações de moradores na gestão do Programa. Embora compartilhe dos princípios do Programa Saúde da Família (PSF), implantado pelo Ministério da Saúde em âmbito nacional a partir de 1995, apresentando similaridades, o PMF de Niterói confere muitas especificidades, sendo anterior ao PSF e uma de suas fontes inspiradoras. 
O PMF é direcionado prioritariamente à população residente em áreas de risco social e ambiental, definidas em um trabalho interinstitucional coordenado pela Prefeitura Municipal de Niterói (PMN, 1992), denominado Diagnóstico Ambiental, que afirma a existência de 70 comunidades com pouca ou nenhuma infra-estrutura sanitária e composta, em sua grande maioria, por famílias com renda inferior a 10 salários mínimos. Estas comunidades representam cerca de $30 \%$ da população total do município, o que corresponde a aproximadamente 138.000 habitantes, compondo a chamada "cidade informal", apontada, naquele documento, como parte da cidade que cresceu sem o planejamento formal, sem a adequada atenção das políticas sociais ao longo dos anos. Trata-se, portanto, de um programa destinado explicitamente àqueles segmentos populacionais mais vulneráveis e com uma história de dificuldades de acessar os serviços de saúde, constituindo-se numa estratégia de discriminação positiva no interior de um sistema universalizado como o SUS.

Por outro lado, a equipe de implantação do PMF indicava que os módulos deveriam ser implantados em áreas com alguma estrutura ambiental, mesmo que mínima, para que a assistência do PMF não viesse a seguir fluxo natural de cura e reincidência, em virtude das péssimas condições ambientais. Vale ressaltar, no entanto, que, segundo depoimento da coordenação do Programa, a entrada do PMF conferia maior status à comunidade, estimulando uma maior capacidade de mobilização e potencializando a conquista de certos direitos de cidadania, conseguindo trazer bens e serviços para sua área.

Nesta perspectiva, o PMF busca atingir bairros ou aglomerações populacionais de baixa renda, entre 3.500 a 4.000 habitantes. As comunidades são divididas por setores delimitados geograficamente, segundo área de moradia, abrangendo aproximadamente 1.000 pessoas ou 250 famílias. Cada setor é acompanhado por uma equipe básica composta por um médico e um auxiliar de enfermagem. Todos os moradores de cada setor são cadastrados, através de prontuários individuais e familiares. A família é considerada o núcleo central da atenção à saúde. Os indivíduos e suas condições de moradia, trabalho, alimentação, educação e lazer, entre outras, interagem com uma equipe de profissionais orientados ao diagnóstico de situações que afetem o seu bem-estar, compartilhando responsabilidades no encaminhamento das soluções para cada caso detectado.
A equipe básica trabalha em horário integral (40 horas semanais), dividido em atendimento nos consultórios dos módulos e atividades de campo, o que inclui a realização de visitas domiciliares, visitas hospitalares e ações de educação em saúde. O programa preconiza o acompanhamento e intervenção nas situações de risco às quais a população está exposta, resgatando o papel social que cabe à saúde. $\mathrm{O}$ médico atua como generalista, com a perspectiva de possibilitar a atenção integral, continuada e setorizada aos indivíduos e suas famílias, com ênfase na promoção e prevenção em saúde, além do diagnóstico precoce e tratamento oportuno. Uma equipe interdisciplinar de especialistas, composta por pediatras, gineco-obstetras, clínicos, psiquiatras, assistentes sociais, enfermeiros, psicólogos e sanitaristas, exerce a função de gerenciar todos os módulos do PMF, dando suporte e supervisão periódica, através de visitas aos consultórios, da realização de interconsultas, do planejamento das atividades em conjunto com a equipe básica e do desenvolvimento de treinamento em serviço e educação continuada.

Através de um decreto do Legislativo municipal, a sociedade civil organizada, via associações de moradores, é co-gestora do programa junto à Fundação Municipal de Saúde. Cabe às associações de moradores a contratação de recursos humanos para o programa, com repasse de verbas do município para este fim. Estas associações podem indicar os componentes das equipes, mas é a coordenação municipal, através das equipes de supervisão, quem seleciona, acompanha e avalia, do ponto de vista técnico, os profissionais da equipe básica. É prevista, pelo convênio de gestão, a participação das associações na gestão administrativa e na avaliação de desempenho das equipes.

Em face destas inovações, a equipe gestora do PMF afirma constantemente o papel "provocador de mudanças” que o programa exerce sobre a rede convencional, impulsionando, a partir de sua prática, um novo rearranjo no sistema de saúde local. Parte-se do entendimento de que a municipalização, embora permita ao nível local maior poder decisório sobre os rumos da política setorial, não garante, por si só, mudanças no padrão de atenção à saúde. Neste sentido, o PMF se constituiria na estratégia para reorganização dos serviços, a partir da atenção básica, mas acarretando alterações nos outros níveis do sistema. De fato, são percebidas mudanças organizacionais na estrutura da prestação de serviços de saúde no município após a 
implantação do PMF, ainda que isto não se dê isoladamente, mas no bojo de um processo mais amplo de redefinição da política de saúde no país e suas especificidades no nível local.

Ao mesmo tempo, é forçoso reconhecer que o formato do modelo assistencial não é dado $a$ priori, mas constrói-se no cotidiano das relações sociais onde os diversos atores políticos envolvidos tecem arranjos, alianças e confrontos tendo em vista a incorporação de suas demandas pelo aparato público municipal no processo de formulação e implementação do PMF.

Tomamos como eixos dessa discussão não os aspectos relacionados às alterações que o PMF introduz no processo de trabalho em saúde, mas aqueles relativos ao desenho organizacional do programa e sua inserção no sistema local de saúde. Parece-nos que a forma como o programa se articula com a rede de serviços existentes, a construção de estratégias que favoreçam o controle social e as alterações nos mecanismos habituais de gestão de recursos humanos constituem os pontos centrais para o debate em torno da perspectiva de inauguração de um novo modelo de atenção à saúde que o PMF encerra.

\section{A inserção do PMF no sistema local}

A emergência do PMF em Niterói como estratégia de reorientação do modelo assistencial foi, de certa forma, impulsionada pelo processo de descentralização do setor saúde em curso no país, com o deslocamento da arena decisória setorial para os municípios. De fato, a municipalização da saúde em Niterói, aliada à inserção de profissionais oriundos do antigo Projeto Niterói nos principais cargos da secretaria municipal de saúde, criou as condições para a implantação do PMF na cidade.

Com a municipalização, Niterói teve a rede de serviços sob gestão municipal significativamente ampliada, deparando-se com dificuldades das mais diversas ordens, entre elas a constituição de um novo desenho institucional para o setor. Cohen (2001) afirma que a descentralização no município ocorreu em ritmo acelerado, num curto espaço de tempo, o que gerou dificuldades na própria estruturação da máquina burocrática. As conseqüentes mudanças organizacionais não permitiram romper basalmente com a estrutura anterior e constituíram o novo desenho institucional a partir de sua velha configuração. Talvez esse seja um dos fatores explicativos para o fato de o PMF surgir como uma estrutura paralela à rede de serviços de saúde constituída no município.

Na mesma direção, Senna (1995), ao analisar o processo de formulação e implementação inicial do programa, entende que a implantação do PMF através de uma estrutura informal e paralela foi uma escolha construída a partir das características do embate técnico-político ao longo do processo, sugerindo dificuldades no enfrentamento de questões fundamentais na constituição do modelo assistencial.

A contratação dos profissionais através das associações de moradores, por exemplo, permitiu uma remuneração acima dos níveis salariais pagos pelo município, ao mesmo tempo em que criou a possibilidade de contratação sem concurso público e de demissão, o que polemizou opiniões em torno da questão. O salário diferenciado foi, inicialmente, um ponto de grande tensão entre o PMF e os profissionais da rede de saúde, que se sentiam preteridos em relação ao programa, repercutindo na sua integração ao sistema local.

Não só os melhores salários pagos aos profissionais do PMF, mas suas condições mais favoráveis de trabalho e estrutura organizacional constituíram-se nos pontos nevrálgicos dos conflitos estabelecidos entre o programa e a rede de serviços de saúde. De fato, desde o seu início, o PMF se constitui numa política prioritária da Secretaria Municipal de Saúde e da própria prefeitura, contando com um expressivo aporte financeiro oriundo do Tesouro Municipal. Vale destacar que os primeiros anos da década de 1990, momento no qual emergiu o PMF, foram marcados por fortes restrições financeiras no país, que se refletiram na diminuição do volume total de recursos para o setor saúde. Assim, a prioridade municipal ao PMF se deu num contexto onde a rede convencional enfrentava uma grave crise financeira, o que certamente provocou impacto na relação do programa com o restante do sistema local de saúde.

O estabelecimento de um sistema de referência e contra-referência é uma questão não enfrentada pelo PMF nos seus primeiros anos de implementação. O encaminhamento a outros níveis de complexidade se dava basicamente através de mecanismos informais que condicionam/facilitam o acesso da população a determinados serviços. Deste modo, o próprio PMF utilizava-se do intercâmbio informal dos médicos como forma de garantir um acesso mais facilitado e personalizado às clínicas especializadas, $\mathrm{o}$ que aponta para a necessidade de relativizar a 
noção de instauração de um novo padrão de atenção à saúde no município proposto pelo programa.

Mudanças nesse quadro podem ser percebidas a partir de 1995, quando o município se habilitou à condição de gestão semiplena. Com essa forma de gestão, proposta na NOB/93, garantiu-se o repasse financeiro automático do fundo nacional para o fundo municipal ao mesmo tempo em que o município adquiriu responsabilidade legal pela gestão de todo o sistema municipal de saúde, aí incluindo os serviços próprios e os privados conveniados e/ou contratados, passando a ter maior autonomia gerencial. Neste processo, Niterói consolidou sua posição de município pólo de referência.

Com o enquadramento na gestão semiplena, chegaram mais recursos para o setor saúde, sobretudo os oriundos da fonte SUS, como mostra o tabela 1. A evolução do dispêndio na saúde em Niterói assinala o investimento do município para assegurar a descentralização das ações de saúde. Após 1995, percebe-se um maior investimento de recursos provenientes do Ministério da Saúde no município, com reflexo direto na produção de serviços na rede pública local.

Com o incremento de recursos para o município, houve um aumento do investimento nas unidades de saúde, que passavam por sérias restrições financeiras. Isto muito ajudou para a melhoria da relação entre o PMF e a rede convencional, uma vez que um dos argumentos contrários ao programa era o fato de haver aplicação satisfatória de recursos enquanto a rede passava por um momento financeiro crítico. Era difícil compreender os motivos de investimento em uma nova proposta, pois a rede relacionava dificuldades do sistema aos problemas de ordem financeira e organizacional e não aos aspectos técnico-metodológicos.

De fato, o investimento na rede convencional, com aumento da complexidade de algumas unidades transformando seu perfil assistencial e a implantação de serviços estratégicos comuns

Tabela 1

Evolução do dispêndio global na saúde de Niterói por fonte de recursos

(1991-2000) - valores em reais

\begin{tabular}{lrrrr}
\hline Fonte de recursos & Tesouro Municipal & \multicolumn{1}{c}{ SUS } & \multicolumn{1}{c}{ Outros } & \multicolumn{1}{c}{ Total } \\
\hline 1991 & $2.888 .378,78$ & $7.313 .642,53$ & $82.308,38$ & $10.284 .329,69$ \\
& $(28,09 \%)$ & $(71,11 \%)$ & $(0,80 \%)$ & $(100,00 \%)$ \\
1992 & $4.621 .209,27$ & $6.779 .754,96$ & $90.534,14$ & $11.491 .498,37$ \\
& $(40,21 \%)$ & $(59,00 \%)$ & $(0,79 \%)$ & $(100,00 \%)$ \\
1993 & $4.521 .880,00$ & $5.123 .544,00$ & $439.527,00$ & $10.084 .951,00$ \\
& $(44,84 \%)$ & $(50,80 \%)$ & $(4,36 \%)$ & $(100,00 \%)$ \\
1994 & $10.696884,00$ & $8.059 .609,00$ & $523.474,00$ & $19.279 .967,00$ \\
& $(55,48 \%)$ & $(41,80 \%)$ & $(2,72 \%)$ & $(100,00 \%)$ \\
1995 & $22.126 .117,31$ & $29.385 .246,06$ & $530.750,29$ & $52.042 .113,66$ \\
& $(42,52 \%)$ & $(56,46 \%)$ & $(1,02 \%)$ & $(100,00 \%)$ \\
1996 & $25.926 .086,51$ & $45.293 .816,82$ & $390.383,10$ & $71.610 .286,43$ \\
& $(36,20 \%)$ & $(63,25 \%)$ & $(0,55 \%)$ & $(100,00 \%)$ \\
1997 & $27.887 .618,40$ & $51.801 .426,42$ & $825.597,86$ & $80.514 .642,68$ \\
& $(34,64 \%)$ & $(64,34 \%)$ & $(1,02 \%)$ & $(100,00 \%)$ \\
1998 & $33.783 .020,15$ & $59.034 .838,58$ & $1.145 .593,00$ & $93.963 .451,73$ \\
& $(35,00 \%)$ & $(62,00 \%)$ & $(3,00 \%)$ & $(100,00 \%)$ \\
1999 & $31.671 .522,87$ & $56.531 .409,20$ & $927.460,66$ & $89.130 .392,73$ \\
& $(35,00 \%)$ & $(63,00 \%)$ & $(2,00 \%)$ & $(100,00 \%)$ \\
& $33.372 .628,78$ & $50.640 .558,84$ & $1.508 .946,69$ & $85.522 .134,31$ \\
& $(39,03 \%)$ & $(59,21 \%)$ & $(1,76 \%)$ & $(100,00 \%)$ \\
\hline
\end{tabular}

Fonte: Fundação Municipal de Saúde de Niterói

*Dados sujeitos à revisão. 
a ambas as propostas trouxe um grande ganho institucional, com a melhoria da integração no SUS Niterói. A partir desse período, os gestores municipais buscaram uma maior integração do PMF ao sistema local, evidenciada numa grande reformulação na configuração da rede de saúde. Foram estruturadas as policlínicas de especialidades e comunitárias e a Central de Marcação de Consultas e Exames, denominada Divisão de Atendimento ao Usuário (DAU) que, somadas à Central de Internações Hospitalares já existente, tinham e ainda têm por objetivo fortalecer os princípios de hierarquização e integralidade das ações a partir de uma nova forma de organização da rede de serviços de saúde.

Nesta perspectiva, o PMF e as unidades básicas de saúde constituiriam a porta de entrada do sistema local de saúde. O pólo articulador das ações desenvolvidas pela rede básica seria o conjunto de Policlínicas Comunitárias (PC), que atuariam como referência para algumas especialidades médicas, laboratórios de análises clínicas e serviço de imagem. A idéia é que as policlínicas possam oferecer mais tecnologia na atenção básica e garantir maiores níveis de resolutividade à população residente nas áreas de abrangência das unidades, sobre as quais exerce autoridade sanitária.

As Policlínicas de Especialidades, através da DAU, responderiam às demandas mais complexas, absorvendo a maior parte das referências não respondidas pelas Policlínicas Comunitárias. Em um nível ainda maior de complexidade, encontrar-se-ia a rede hospitalar própria e conveniada, que, através da DAU e da central de internações, ofereceria serviços de internação hospitalar, emergência, exames mais complexos e consultas em algumas especialidades.

A estruturação de um sistema de referência e contra-referência, nesta perspectiva, procurava garantir o acesso do usuário a todos os níveis do sistema. A criação da DAU buscou permitir às unidades de primeiro nível (módulos médico de família e unidades básicas de saúde) a garantia de atendimento de sua clientela adscrita nas unidades de maior nível de complexidade tecnológica, segundo critérios de regionalização. Essa configuração do modelo de atenção à saúde no município se mantém até hoje.

Para além do incremento nos recursos destinados à rede de saúde, um fator importante para estruturação das bases do sistema e para facilitar a integralidade das ações foi a duradoura coalizão política em Niterói, capaz de ocupar o governo e permitir a sua continuidade, favore- cendo a permanência da equipe gestora da saúde por longo período (cerca de 12 anos), sem alterações significativas de seus quadros. Além disso, o fato de a coordenação geral do programa ficar a cargo da vice-presidência de atenção ambulatorial (coletiva e da família, responsável pela gestão de toda a rede ambulatorial) aliado à centralização financeira na FMS contribuíram no sentido de buscar a integração do PMF ao sistema local.

O êxito do PMF junto à população também levou o programa a ser respeitado por toda a rede, que passou a compreender e a buscar reproduzir a sua metodologia. A adoção do Programa Saúde da Família (PSF) pelo Ministério da Saúde como estratégia reorientadora da atenção básica, a partir de 1995, e o reconhecimento externo do PMF, com várias premiações, também colaboraram neste sentido.

Apesar disso, observa-se que ainda persistem dificuldades de integração entre o PMF e a rede convencional, tendo o programa mantido uma estrutura autônoma de gerência. Nota-se a ainda fragilidade das estratégias de vinculação utilizadas, que enfrentam muitas dificuldades para sua operacionalização, sobretudo em relação aos recursos humanos. Na rede convencional, por motivos como a carga horária reduzida e a ausência de uma equipe de saúde pública instituída formalmente para o trabalho extramuros, algumas tentativas de adscrever a população ao profissional fracassaram.

$\mathrm{Na}$ verdade, o que se percebe é a existência de dois modelos em constante tensão, nos quais os atores de cada proposta configuram diversas alianças e rupturas em torno de interesses, estabelecendo momentos de pactuação e de conflitos.

Efetivamente, a partir de 1998, as bases para a ampliação dos conceitos de territorialidade $\mathrm{e}$ de responsabilidade sanitária foram postas à medida que o município assumiu a gestão plena do Sistema de Saúde (NOB/96), consolidando a reorganização da rede de serviços e buscando aperfeiçoar a estrutura administrativa, na construção de canais para a intersetorialidade. A III Conferência Municipal de Saúde, realizada em 1999, teve como eixos de discussão questões como intersetorialidade, ações integradas articuladas no contexto do território, participação popular e controle social, responsabilidade sanitária, satisfação da clientela e humanização dos serviços, sob a ótica da reforma do Estado, do modelo assistencial e da política de recursos humanos e de financiamento. As idéias convergi- 
ram para solidificação das policlínicas como organizadoras do espaço regional e foi proposta a "ampliação do número de policlínicas comunitárias, conjugando necessidade demográfica com perfil epidemiológico da população" (III CMS, 1999). A Conferência se constituiu em espaço de defesa do Programa Médico de Família pelas associações de moradores, que, por considerá-lo a principal estratégia para solução dos problemas de saúde da comunidade, reivindicaram sua ampliação para as demais localidades.

Apesar da demonstração na III Conferência, junto à população organizada, da consolidação do modelo assistencial, muitos problemas foram apontados, sobretudo os referentes ao desenvolvimento de ações integradas de saúde, demonstrando que a articulação entre os vários níveis do sistema local de saúde ainda tem muito que avançar.

Deve-se ressaltar que, na verdade, os problemas relativos à integração entre o PMF e a rede convencional não são específicos do programa, mas dizem respeito à própria forma de constituição do sistema de saúde. Refletem, em grande parte, as dificuldades relativas ao processo de descentralização, além das inerentes às adequações estruturais para implementação de novas estratégias vis-à-vis à herança cultural deixada pelo modelo hospitalocêntrico. Essas dificuldades estão presentes no processo de integração da rede ambulatorial e hospitalar, na relação do setor público com o privado, no processo de planejamento e avaliação no SUS, na participação do usuário e na implementação de ações intra e intersetoriais. São, portanto, desafios à própria consolidação do SUS.

\section{O controle social no PMF}

Uma das inovações trazidas pelo PMF refere-se à institucionalização de mecanismos que permitem a participação popular e o controle social. Estes mecanismos se consubstanciam tanto na co-gestão do programa pela FMS e pelas associações de moradores locais quanto na própria metodologia do programa e seu processo de trabalho.

A co-gestão do programa foi estabelecida através de um minucioso convênio entre FMS e associações de moradores, no qual se definiu o papel da coordenação e da supervisão do programa, além das competências e atribuições da associação de moradores e da própria Fundação Municipal de Saúde. O convênio garantiu, ainda, o repasse - diretamente da Secretaria Municipal de Finanças e Desenvolvimento Econômico para a FMS - de recursos financeiros previstos no orçamento municipal especificamente para este fim.

Um aspecto presente na proposta original do programa era propiciar uma efetiva organização da população local, como forma de favorecer a mobilização comunitária, divulgar a proposta do programa e facilitar a inserção da equipe na comunidade. O PMF, assim, estabelece um espaço institucionalizado para vocalização das demandas populares.

De fato, desde sua formulação, o programa vem se constituindo em um estímulo à organização comunitária e à autonomia das comunidades. Após a implantação do PMF, as comunidades adquirem uma maior mobilização, conquistando outros benefícios e ampliando os direitos dos quais se encontravam excluídas.

De forma indubitável, o acesso à assistência médica propiciado pelo PMF se constitui numa demanda legítima dos movimentos sociais organizados no reconhecimento do seu direito à saúde. Para as associações de moradores, o PMF representa, mais do que a assistência médica, a garantia de acesso à figura do mais alto posto da hierarquia da equipe de saúde, consubstanciada na modificação da relação médico-paciente. A presença do médico cotidianamente nas comunidades, atendendo aos moradores de áreas tradicionalmente desprovidas de equipamentos sociais urbanos, é percebida como privilégio antes concedido apenas para as classes de alto poder aquisitivo.

Por outro lado, a contratação de pessoal da equipe básica pela associação de moradores traz a possibilidade de maior controle social sobre o horário e a qualidade do trabalho dos médicos. Desde o início, esta forma de controle tem desenhado, muitas vezes, um quadro tenso na relação do médico de família com as associações de moradores, em face do papel fiscalizador assumido por estas e seu poder de ameaça sobre o pagamento e demissão dos profissionais, inclusive do médico.

Há que se considerar que o processo de formulação e implementação do PMF em Niterói revela um quadro particular de alianças e acordos entre atores sociais ligados à questão saúde no município. De certa forma estimulados pelo clima de participação popular que irrompe os anos 90 e com base na experiência acumulada com o Projeto Niterói, setores da burocracia municipal da saúde buscaram interlocução com 
os movimentos sociais locais organizados no processo de formulação do PMF. Neste processo, foram eleitos como interlocutores privilegiados a Federação das Associações de Moradores de Niterói (Famnit) e as associações de moradores a ela vinculados, enquanto outros segmentos de grande visibilidade política no município, como os conselhos comunitários e o movimento de profissionais de saúde, são excluídos da arena decisória. O privilegiamento destes setores, sem uma interação mais consistente com as demandas e os interesses dos demais grupos, estabeleceu limites para um projeto mais amplo de reordenação da rede de serviços de saúde no município, muito embora mudanças neste processo venham sendo experimentadas mais recentemente.

Vale mencionar que os dirigentes das associações de moradores em contrato de co-gestão com o PMF se destacam das demais lideranças populares, tornando-se atores privilegiados no processo político municipal. Adquirem também maior destaque como indivíduos dentro de suas comunidades. Ao mesmo tempo, o fato de a Famnit se constituir no interlocutor direto com o poder público no que se refere à participação comunitária na saúde, sobretudo no PMF - é pré-requisito para o contrato com o programa que a Associação de Moradores seja filiada a Famnit -, fortalece esta Federação frente às demais instituições da sociedade civil organizada no município.

A participação popular e o controle social também se consubstanciam na organização do processo de trabalho no PMF. Após definição da área onde será implantado o módulo do programa, a equipe de supervisão parte para a setorização, onde, junto com a associação de moradores local, visita casa a casa, explica aos moradores o funcionamento do programa e realiza as primeiras reuniões de setor, buscando a mobilização comunitária para que a população usuária possa se inserir como sujeito do processo saúde/doença.

A aproximação com a comunidade se processa através de várias estratégias, que vão da abordagem diferenciada no cuidado individual ao incremento das reuniões com a comunidade e dos trabalhos em grupo. A visita domiciliar é também uma estratégia importante de aproximação com a comunidade. É neste momento que a equipe básica interage com a família e percebe seus hábitos, suas crenças, a forma como se relaciona com familiares e vizinhos e os laços de solidariedade que os une, fatos essenciais para o desenvolvimento das ações de saúde.
Também fazem parte da rotina das equipes as reuniões e práticas educativas participativas, que buscam introduzir, de forma sistêmica, o propósito de cumprir o papel social que cabe à saúde. Entre as reuniões sistemáticas, destacase como aspecto metodológico fundamental na organização do PMF a reunião mensal de setor. Nestes encontros, a equipe básica, a supervisão e a associação de moradores se juntam à comunidade para discussão dos problemas de saúde e avaliação do trabalho e da própria equipe. $\mathrm{Pa}$ ra facilitar o acesso da população, estas reuniões são, geralmente, realizadas à noite.

Vale ressaltar que, apesar de todas as estratégias apresentadas, o processo de participação popular no programa enfrenta uma série de dificuldades e conflitos, alguns dos quais inerentes à própria dinâmica dos atuais movimentos sociais e a uma cultura cívica e democrática ainda bastante frágil.

O fato é que a experiência de controle social proporcionada pela co-gestão do PMF vem sendo amadurecida ao longo do tempo. De acordo com Cohen (2001), pode-se mesmo afirmar que, no atual momento, a despeito das dificuldades encontradas, a formulação da política setorial e o processo de implementação do SUS local contam com a participação efetiva da população organizada, tendo as associações de moradores se constituído em parceiras diretas no desenvolvimento do PMF.

\section{O PMF e a gestão de recursos humanos}

A forma de contratação dos recursos humanos do PMF parece configurar uma estratégia de flexibilização em relação aos mecanismos tradicionais de gestão de recursos humanos do setor público. De fato, a contratação dos profissionais através das associações de moradores criou a possibilidade de demissão, ao mesmo tempo em que permitiu uma remuneração acima dos níveis salariais pagos pelo município, o que polemizou opiniões em torno da questão.

Para os gestores do programa, esta seria uma saída deliberada a fim de evitar as "armadilhas" do funcionalismo público, onde a estabilidade do emprego tem sido associada a baixos índices de produtividade, acomodação e ineficácia.

Assim, diferentemente do vínculo empregatício com a FMS, os profissionais no PMF são contratados pelo regime de CLT, em tempo integral, por 40 horas semanais, a serem cumpridas em módulos de consultórios dentro das co- 
munidades, sob supervisão metodológica, qualificação técnica e avaliações sistemáticas.

Os médicos de família são escolhidos através de seleção pública, com base em edital divulgado em jornais de grande circulação. Submetemse a uma análise de currículo e a uma entrevista individual, de caráter eliminatório, em que se avaliam seu conhecimento técnico e seu perfil profissional. Informações fornecidas pela coordenação do PMF apontam que a procura para ingresso no programa tem sido cada vez maior, com envio de grande quantidade de currículos para o processo seletivo. A seleção é realizada por uma banca de profissionais da coordenação e supervisão, respeitando critérios previamente estabelecidos. O mesmo acontece com os auxiliares de enfermagem, cuja convocação se dá através de divulgação na própria comunidade, uma vez que a residência no local a ser implantado o módulo é pré-requisito.

Já na rede convencional, ao contrário, os profissionais são funcionários públicos municipais, estaduais e/ou federais municipalizados, e cada qual recebe salário de acordo com o teto fixado por seu órgão de origem, existindo, assim, diferentes salários para uma mesma função. Este é um grande problema presente no SUS desde sua origem, quando estava em pauta a questão da isonomia salarial.

Este aspecto relativo aos recursos humanos no SUS, polêmico no cenário nacional, configurou-se como grande problema na implementação do PMF em Niterói. Os profissionais da rede convencional questionaram os altos salários pagos à equipe técnica do programa, aproximadamente três vezes mais do que o de um profissional da mesma especialidade na rede convencional.

Para justificar a diferença salarial, os profissionais do PMF afirmam que, se considerada a hora trabalhada e os benefícios que os profissionais da rede convencional podem usufruir formalmente, como, por exemplo, licença-prêmio e licença-amamentação, somados aos informais, como o day-off e a facilidade de licença médica, não haveria uma diferença significativa entre os dois salários. No entanto, este é um item que gerou muitos atritos entre a rede convencional e o PMF, principalmente no seu início.

Por outro lado, é preciso salientar que, na realidade, muitos dos profissionais que atuam no PMF, sobretudo na equipe de coordenação e supervisão, são funcionários públicos que estão licenciados dos seus vínculos, ou têm contrato parcial com o PMF, como forma de complemen- tar sua carga horária. Mesmo assim, é comum ouvir de profissionais do PMF que os profissionais da rede convencional não têm jeito e que não se pode contar com eles.

Esta é, de fato, uma área muito conflituosa, com sérias repercussões no desenho do sistema local, sobretudo porque a rede de referência no SUS local é composta, em sua maioria, por funcionários públicos. Este aspecto, somado aos conflitos no corpo gestor da Fundação Municipal, quando da origem do PMF, certamente dificulta o processo de integração do programa à rede convencional e a atuação conjunta dos diversos atores da rede SUS-Niterói, constituindo mais um dos desafios a serem enfrentados pelos gestores locais.

\section{Considerações finais}

A descentralização municipal, que vem marcando a política de saúde recente, tem, certamente, introduzido um conjunto de alterações no desenho da engenharia institucional do setor, permitindo ao nível local maior poder de decisão sobre os rumos da política setorial. Há que se considerar, no entanto, que a descentralização, por si só, não garante a mudança no padrão de atenção à saúde.

Em Niterói, a municipalização do setor, aliada à inserção de profissionais oriundos do Projeto Niterói na Secretaria Municipal de Saúde, criou, sem dúvida, as condições para o surgimento do PMF na cidade. Por outro lado, numa via de mão dupla, a própria implantação do programa tem produzido impactos na organização dos serviços no nível local.

$\mathrm{Na}$ perspectiva de seus formuladores, o PMF - como iniciativa da burocracia municipal da saúde - encerra a possibilidade de inauguração de um novo padrão de atenção à saúde no município. A ampliação da rede básica, com a implantação de módulos de médico de família se constituiria, nesta direção, uma das estratégias para reverter o modelo de assistência tradicional e para uma aproximação mais estreita com a população, perseguindo, assim, os princípios de universalização do acesso, integralidade da ação, hierarquização e controle social.

Há que se considerar, no entanto, que o modelo assistencial não é dado a priori, mas constrói-se no cotidiano das relações políticas entre os diversos atores sociais com poderes diferenciados no que se refere à incorporação de suas demandas pela agenda estatal. Neste sentido, é 
a arena de interesses em torno do PMF quem redefine o desenho técnico-institucional desta política.

A implantação do PMF através de uma estrutura paralela à rede de serviços foi uma opção construída a partir das características do embate técnico-político ao longo do processo. Diferentemente de Cuba, onde a medicina familiar é a porta de entrada do sistema de saúde cubano, o caráter do PMF em Niterói como programa paralelo restringiu o enfrentamento de problemas em torno da totalidade da oferta dos serviços de saúde do município. Além disso, a ausência de uma rede de referência impôs limites ao acesso dos usuários a outros níveis de complexidade.

Mudanças neste perfil têm sido propostas a partir de 1995, quando o município ganha maior autonomia técnico-gerencial em virtude da habilitação à condição semiplena. Desde então, o processo de integração do PMF ao sistema local tem sido construído a partir de uma estratégia gerencial. Com a implantação do PMF, a FMS tem o propósito de consolidar um modelo capaz de responder aos princípios constitucionais do SUS, instituindo um único gestor para a atenção básica no município, de forma a não haver segmentação entre a gestão do PMF e da rede convencional.

No entanto, os avanços têm sido lentos e as mudanças no modelo assistencial pretendidas pelo PMF exigem que se vença a forma tradicional de organização dos serviços e se incorporem, em toda a rede, os fundamentos do modelo de vigilância em saúde.

Certo é que os problemas relativos a esta integração não são específicos do programa, mas dizem respeito a um conjunto mais amplo de questões que vêm marcando historicamente o padrão da oferta dos serviços de saúde no Brasil.

Mas isto não significa que o PMF não possa induzir a mudanças no padrão da oferta de serviços no município. Na verdade, o programa é considerado, pelos gestores da FMS, a prioridade para reorientação do modelo assistencial, sendo concebido como porta de entrada ao sistema local de saúde, sobretudo das comunidades mais vulneráveis ao processo de adoecimento. O PMF busca, neste sentido, efetivar o conceito de responsabilidade sanitária e propor espaços de construção de cidadania, de modo a ampliar o acesso aos recursos disponíveis, na lógica de discriminação positiva. Nesta direção, o programa deve manter com os demais serviços da rede uma política de articulação de forma complementar, hierárquica e regional. Também a rede de serviços precisa ser pensada e repensada na sua forma de atuar, incorporando princípios estratégicos na concretização das diretrizes do SUS. Este é o desafio.

\section{Referências bibliográficas}

Almeida C M 1999. Reforma do Estado e reforma de sistemas de saúde: experiências internacionais e tendências de mudança. Revista Ciência \& Saúde Coletiva 4(2):263-286.

Almeida MHT 1996. Federalismo e políticas sociais, pp. 13-40. In RBA Affonso \& PLB Silva (orgs.). Federalismo no Brasil: descentralização e políticas sociais. FUNDAP, São Paulo.

Bodstein RC 1996. Inovações na análise de oolítica no campo da saúde, pp. 157-172. In NR Costa \& JM Ribeiro (orgs.). Política de Saúde e Inovação Institucional. Ensp/Fiocruz, Rio de Janeiro.

Cohen MM 2001. O modelo assistencial no SUS - Niterói: conflito e pactuação política no processo de integração do Programa Médico de Família. Dissertação de mestrado. Escola Nacional de Saúde Pública, Fundação Oswaldo Cruz, Rio de Janeiro, 216pp.
PMN 1992. Diagnóstico ambiental. Prefeitura Municipal de Niterói, mimeo.

PMN/SECITEC 1999. Niterói: perfil de uma cidade. Prefeitura Municipal de Niterói, 284pp.

Senna MCM 1995. Municipalização e controle social: o Programa Médico de Família em Niterói (1992-1994). Dissertação de mestrado. Escola Nacional de Saúde Pública, Fundação Oswaldo Cruz, Rio de Janeiro, 122pp.

Silva Jr AG \& Oliveira GS 1993. Participação popular e políticas de saúde em Niterói/RJ (1970-1992). UFF/PMN, mimeo.

Souza C \& Carvalho IMM 1999. Reforma do Estado, descentralização e desigualdades. Lua Nova 48:187-212.

Artigo apresentado em 8/3/2002

Versão final apresentada em 12/8/2002

Aprovado em 19/8/2002 